\title{
Sperm removal during copulation confirmed in the oldest extant damselfly, Hemiphlebia mirabilis
}

Adolfo Cordero-Rivera

Postcopulatory sexual selection may favour mechanisms to reduce sperm competition, like physical sperm removal by males. To investigate the origin of sperm removal, I studied the reproductive behaviour and mechanisms of sperm competition in the only living member of the oldest damselfly family, Hemiphlebia mirabilis, one species that was considered extinct in the 1980s. This species displays scramble competition behaviour. Males search for females with short flights and both sexes exhibit a conspicuous "abdominal flicking". This behaviour is used by males during an elaborate precopulatory courtship, unique among Odonata. Females use a similar display to reject male attempts to form tandem, but eventually signal receptivity by a particular body position. Males immobilise females during courtship using their legs, which, contrarily to other damselflies, never autotomise. Copulation is short (range 4.1-18.7 $\mathrm{min}$ ), and occurs in two sequential stages. In the first stage, males remove part of the stored sperm, and inseminate during the second stage, at the end of mating. The male genital ligula matches the size and form of female genitalia, and ends by two horns covered by back-oriented spines. The volume of sperm in females before copulation was 2.7 times larger than the volume stored in females whose copulation was interrupted at the end of stage I, indicative of a significant sperm removal. These results point out that sperm removal is an old character in the evolution of odonates, possibly dating back to the Permian. 
2 Sperm removal during copulation confirmed in the oldest

3 extant damselfly, Hemiphlebia mirabilis

4

5

6

7 Adolfo Cordero-Rivera

8 ECOEVO Lab, Universidade de Vigo, EUE Forestal, Campus Universitario

936005 Pontevedra, Spain

10

11 adolfo.cordero@uvigo.es

12

13 Running head: Reproductive behaviour of Hemiphlebia mirabilis

14 Word count: 4936 


\section{Abstract}

16 Postcopulatory sexual selection may favour mechanisms to reduce sperm competition, like

17 physical sperm removal by males. To investigate the origin of sperm removal, I studied the

18 reproductive behaviour and mechanisms of sperm competition in the only living member of the 19 oldest damselfly family, Hemiphlebia mirabilis, one species that was considered extinct in the 20 1980s. This species displays scramble competition behaviour. Males search for females with 21 short flights and both sexes exhibit a conspicuous "abdominal flicking". This behaviour is used 22 by males during an elaborate precopulatory courtship, unique among Odonata. Females use a 23 similar display to reject male attempts to form tandem, but eventually signal receptivity by a 24 particular body position. Males immobilise females during courtship using their legs, which, 25 contrarily to other damselflies, never autotomise. Copulation is short (range 4.1-18.7 min), and 26 occurs in two sequential stages. In the first stage, males remove part of the stored sperm, and 27 inseminate during the second stage, at the end of mating. The male genital ligula matches the 28 size and form of female genitalia, and ends by two horns covered by back-oriented spines. The 29 volume of sperm in females before copulation was 2.7 times larger than the volume stored in 30 females whose copulation was interrupted at the end of stage I, indicative of a significant sperm 31 removal. These results point out that sperm removal is an old character in the evolution of 32 odonates, possibly dating back to the Permian. 


\section{Introduction}

35 The relevance of Sexual Selection in shaping reproductive behaviour is well established

36 (Andersson, 1994), and in particular its effects on the evolution of primary (Leonard \& Córdoba-

37 Aguilar, 2010) and secondary sexual characters (Clutton-Brock, 2007). Our understanding of

38 sexual selection processes is based on the conceptual framework that differentiates between pre-

39 copulatory and post-copulatory forces and mechanisms (Eberhard, 1996), and the traditional

40 differentiation of intra- and inter-sexual selection, which can be dated back to the original texts

41 of Darwin (1871). The origin and maintenance of many bizarre behaviours is explained by

42 sexual selection theory, even if such behaviours may not be favoured by natural selection. Males

43 and females do not necessarily have the same interests, and conflicts are expected (Parker, 1979;

44 Arnqvist, 2004), which are particularly evident in species whose females store sperm for long

45 periods. Animal genitalia are therefore under intense sexual selection (Eberhard, 1985), and this

46 may drive coevolutionary arm races between sexes (e.g. Sánchez \& Cordero, 2014).

47 Several mechanisms explain the evolution of male reproductive strategies, both to increase

48 paternity when competing with other males, and to reduce the success of other males in the

49 context of sperm competition (for a review, see Cordero Rivera \& Córdoba Aguilar, 2016).

50 Perhaps the most surprising adaptation is the ability to physically remove the sperm from rivals,

51 stored inside the female, using the intromittent organ. In a seminal paper, Waage (1979)

52 demonstrated, for the first time, that male damselflies are able to use their genital ligula to trap

53 sperm from previous mates, and remove them during copulation, so that paternity success of the

54 last male is usually near $100 \%$ in the first clutch laid after copulation (e.g. Cordero \& Miller,

55 1992). Since Waage's discovery, the mechanism of sperm removal by males has been

56 demonstrated in several animal groups, including Dermaptera (Kamimura, 2005), Orthoptera 
57 (Ono, Siva-Jothy \& Kato, 1989; von Helversen \& von Helversen, 1991) and Coleoptera (Yokoi,

58 1990) among the insects, but also in Crustaceans (Galeotti et al., 2008) and Cephalopods (Wada

59 et al., 2010). This is therefore a widespread phenomenon in animals, which has apparently

60 evolved several times, but we have little information about its origin in any animal group.

61 Although Odonates are well known model species for studies of sexual selection and

62 evolutionary biology in general (Córdoba-Aguilar, 2008), most research has been confined to a

63 few families (Cordero-Rivera and Córdoba-Aguilar 2010). This taxonomic bias might induce

64 wrong interpretations about the generality of some behaviours. We do not have fossil

65 information to track the evolution of significant behaviours, like the ability to remove sperm

66 from previous mates when a male copulates with a female. An alternative is to study behaviour

67 on a phylogenetic perspective. Given its basal position in the Zygoptera (Dumont, Vierstraete \&

68 Vanfleteren, 2010), Hemiphlebia mirabilis, the only living member of the Hemiphlebiidae, is a

69 priority taxon in this context. This family dates back to the late Jurassic at least (Lak et al.,

70 2009), and H. mirabilis has been considered a "living-fossil", a survival from the Permian

71 (Fraser, 1955).

72 The goals of this study were therefore two fold. First, I wanted to observe and describe the

73 reproductive behaviour of this species, that has been up to now unknown. Fraser (1955)

74 published a description of the male intromittent organ (genital ligula), noting that it had two

75 flagella or horns similar to those of other species known to use these structures to remove sperm

76 (Córdoba-Aguilar \& Cordero-Rivera, 2008). However, female internal organs remain unknown.

77 Given that female structures are the "arena" where postcopulatory sexual selection takes place,

78 their study is crucial. Therefore, my second goal was to study genital morphology of both sexes

79 and sperm competition mechanisms. If $H$. mirabilis males displace sperm, this would suggest 
80 that sperm displacement and the dual function of male genitalia (Waage, 1979) is an old

81 character in Odonates.

\section{Methods}

83 Most observations and experiments were done at Long Swamp, a large freshwater system in the

84 Discovery Bay Coastal Park, near to Nelson (Victoria, Australia), between 17 November and 7

85 December 2013. Population density of $H$. mirabilis was very high during the field work

86 (Cordero-Rivera, 2016). A second population, inhabiting Ming Ming swamp in Grampians

87 National Park, was visited for further observations.

88 Animals included in this study were individually marked. Having a marked population is a 89 convenient fact for demographical and behavioural studies (Cordero-Rivera \& Stoks, 2008),

90 because individually marked specimens are best for focal observations. Marking was done with a 91 permanent black ink pen (Faber-Castell Multimark $1525 \mathrm{~S}$ ) on the external side of the right hind 92 wing (see Figures 2 and 3).

93 Copulatory behaviour was rarely observed. For instance, I observed one mating on 19 and 25

94 November and two on 26 November. Therefore, I decided to try to increase inter-individual 95 encounters by using a mosquito net as an outdoor insectary, where a set of marked specimens 96 were introduced. The insectary was used to elicit mating behaviour on days 29, 30 November 97 and 1 and 3 December, between 11 and 16-17 h. At the end of the observations, the insectary 98 was removed and remaining individuals released. I observed a total of 28 copulations, of which 9911 were forcibly interrupted at different times to study sperm competition. Three pairs were 100 preserved in copula (at the end of stage I; see Results) and dissected to test whether the genital 101 ligula can physically remove sperm. Furthermore, seven apparently mature females were 102 collected to estimate the sperm volume of pre-copula females. The pair, or sometimes only the 
103 female, was immediately preserved in $70 \%$ ethanol for further analyses. One thermometer was

104 placed in the shade of a shrub at about $1.5 \mathrm{~m}$ over water. Temperature was recorded about once 105 every hour.

106 In the laboratory, females were dissected and the sperm storage organs extracted. Two 107 postcopula females had no sperm in their bursa copulatrix. This fact might be due to failure in 108 insemination (Sánchez-Guillén, Wellenreuther \& Cordero-Rivera, 2011), and these females were 109 excluded from sperm volume analyses. Furthermore, two females collected alone (pre-copula) 110 and also two of the group interrupted during the stage I, had no sperm. These were likely 111 unmated or mating for the first time (and interrupted before insemination), and were also 112 excluded from sperm volume estimations. The sperm storage organs of a further female were 113 accidentally damaged during dissection and could not be analysed. Final sample sizes were 114 therefore five pre-copula females, seven after copulation and six interrupted at the end of stage I. 115 The volume of sperm was estimated following standard protocols (Cordero \& Miller, 1992), 116 using the software ImageJ (http://imagej.nih.gov/ij/) to measure the area of the sperm mass from 117 microscope pictures. Male secondary genitalia were dissected and observed under Scanning 118 Electron Microscope (SEM). Permits to collect odonates were issued by the Victorian 119 Department of Environment and Primary Industries (permit number 10006907).

120 Mean values are presented with their standard error (SE) and sample size: mean $\pm \mathrm{SE}(\mathrm{N})$.

121 Statistical analyses were performed with xlStat 2016 (www.xlstat.com) and Genstat 17

122 (http://www.vsni.co.uk). Sperm volumes were analysed by ANOVA, and groups were compared 123 using pre-copula females as the control, by means of a Dunnett test. 


\section{Results}

125 Reproductive behaviour

126 Hemiphlebia mirabilis showed limited flying activity, and remained perched most of the time.

127 Males were not territorial, and the mating system was found to be scramble competition. The

128 most conspicuous behaviour was abdominal flicking, which occurred continuously over the day,

129 was performed by both sexes, and has been studied elsewhere (Cordero-Rivera, 2016).

130 Mating behaviour was very infrequent. Over the study period, I observed 28 copulations, but

131 only eight of them outside the insectary. Mating behaviour was found to be similar to that of

132 Coenagrionidae, but with several peculiarities. When a male detected a potential partner, he

133 made a fast flight, similar to a feeding flight, and grasped the female by her wings with his legs

134 (Figure 1A). Occasionally, males tried to achieve tandem with other males (even of other

135 species), but this behaviour lasted only a few seconds. Some females curled their abdomen

136 upwards when immobilised by males, and tried to dislodge the male, in a clear refusal behaviour

137 (Figure 2), which was sometimes successful. In the insectary, these tandems that did not end in

138 copula lasted $8.4 \pm 2.4(4)$ minutes.

139 Receptive females remained motionless, and adopted a characteristic position with their

140 abdomen curved downwards in the junction between the first and second abdominal segments,

141 and upwards between third and fourth segments. The position recalls a capital Z (Figures 1B-F

142 and 2C). After a variable time motionless, males started to make their characteristic abdominal

143 flicking, in a clear courtship behaviour (see the sequence in Figure 1B-F, and also Video 1).

144 Then, males curved their abdomen upwards and grasped the females's prothorax with their

145 abdominal appendages (Figure 2C). The average time between female capture and tandem

146 formation was $6.20 \pm 1.17$ (19) minutes, with a range from 1.67 to 23.0 minutes. During this time, 
147 males used their abdominal flicking display to court the females, with motionless periods

148 intercalated. After grasping the female with his anal appendages, the male opened its legs widely

149 and released the female's wings (Video 1).

150 After tandem formation, males performed sperm translocation, from the $9^{\text {th }}$ to the $2^{\text {nd }}$ abdominal

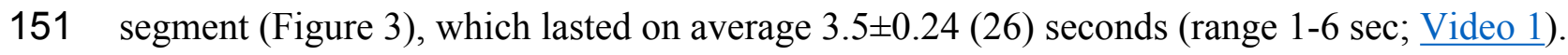

152 This behaviour always preceded copulation, contrarily to what was previously reported (Sant \&

153 New, 1988). Copulation started immediately after sperm translocation. Copulatory movements

154 (see Figure 4) were similar to those in Coenagrionidae, and had two clear phases, which match

155 the description of stage I and II of Enallagma cyathigerum (Miller \& Miller, 1981).

156 Copulation lasted 10.53 \pm 1.17 (14) minutes (range 4.1-18.7 min), and its duration was not

157 significantly related to time of day (Figure 5) or air temperature (Figure 6) (multiple regression

158 analysis with copula duration as the response variable and time of day and temperature as

159 explanatory variables; time effect: $-0.0053 \pm 0.0105, \mathrm{t}_{8}=-0.51, \mathrm{p}=0.624$; temperature effect:

$\left.1600.0008 \pm 0.0006, \mathrm{t}_{8}=1.32, \mathrm{p}=0.224\right)$. The analysis of the duration of courtship and precopulatory

161 tandem also suggested that time of day and temperature have no effect ( $p$-values $>0.10$ ). Most of

162 the variation in copulation duration was due to stage I, which lasted $9.96 \pm 1.30$ (12) minutes.

163 Stage II was of short duration and showed little variability in duration (1.08 \pm 0.11 (13) $\mathrm{min})$. At

164 the end of copulation, all males flew off immediately leaving the female alone, but usually

165 perched nearby. Females either flew $(\mathrm{N}=5)$ or remained perched for a short time $(\mathrm{N}=4)$. One

166 female could be closely observed for about 2 minutes after copula. She apparently did not expel

167 sperm (Córdoba-Aguilar, 2006), but made conspicuous movements of her external genitalia.

168 I did not observe a single female laying eggs. Oviposition does not take place in tandem after

169 mating, so it should be performed by females alone. On 25 November I collected 10 females 
170 apparently mature and put them in plastic containers with humid filter paper, a method that

171 elicits oviposition behaviour in many zygopterans (Van Gossum, Sánchez-Guillén \& Cordero-

172 Rivera, 2003). They were retained for two hours on a shaded spot, and afterwards were released,

173 but none laid eggs. A second attempt to obtain eggs was done with 22 females from the

174 population at Ming Ming Swamp, which were fully mature judging by their enlarged abdomen.

175 Females were maintained with humid filter paper from 12:15 to 15:30 h, but once more, no

176 oviposition was observed. Five females were retained and maintained overnight with humid filter

177 paper and a piece of vegetation, but yet again, no eggs were laid.

178 Anatomy of genitalia and sperm competition

179 Figure 7 shows the anatomy of male genitalia under SEM, and female genitalia under an optical

180 microscope. The genital ligula measures about $2 \mathrm{~mm}$ in length, and ends in a flexible tip,

181 culminated distally by two dorsal horns or cornua (Figure 7A, D). These are covered by

182 backwards oriented spinules (Figure 7F). The genital ligula is also covered by small spinules on

183 both sides (Figure 7E), and by a group of larger spinules on the ventral median part (Figure 7C).

184 Female genitalia show two chitinised plates with embedded sensillae (Figure 7B), and a large

185 bursa copulatrix, full of sperm in postcopula females. There is no spermatheca, although in some

186 specimens the bursa seems to be divided into two parts as in Figure 7B. The size and structure of

187 male genitalia compared to female bursa copulatrix, as well as the presence of spinules, both

188 suggest that males can remove sperm during the stage I of copulation. Three females, preserved

189 in copula, were dissected. The genital ligula was situated between the chitinised plates in all

190 cases, and in one case the distal part was found inside the bursa, showing that physical removal

191 of sperm is possible (the bursa was empty, likely because the female was unmated). 
192 Pre- and postcopula females had their bursa full of sperm, whereas it was almost empty in

193 females interrupted at the end of stage I (Figure 8; ANOVA, $\mathrm{F}_{2,15}=11.12, \mathrm{p}<0.001$ ). The volume

194 of sperm in pre-copula females was 2.7 times greater than the volume stored in females whose

195 copulation was interrupted at the end of stage I (difference= 0.007 , Dunnett test (two-sided)

$196 \mathrm{p}=0.020)$, indicating a significant sperm removal. The volumes of sperm stored by pre- and

197 postcopula females were not significantly different (difference=-0.003; $p=0.293$; Figure 8).

\section{Discussion}

199 The reproductive behaviour of $H$. mirabilis is unique from several points of view. Both sexes

200 frequently perform abdominal flicking, particularly after flights, even in the absence of

201 conspecifics (Cordero-Rivera, 2016). The results of this study indicate that this abdominal

202 display, which is the most conspicuous behaviour of H. mirabilis (Sant \& New, 1988), is also

203 part of the courtship (Figure 1). There have been suggestions in the literature indicating that

204 males use the curling of the abdomen to display to and attract females (Tillyard, 1913), and that

205 females respond to male abdominal flicking by performing the same display (Davies, 1985). My

206 observations nevertheless do not support this. Although to some extent both males and females

207 show this behaviour to conspecifics which are also displaying, females can perform abdominal

208 flicking even more actively than males when they are alone and undisturbed (up to 172 times in

20910 minutes compared to 119 times in males; Cordero-Rivera, 2016). Abdominal displays may

210 also help in intraspecific recognition, or be a "receptivity" signal, but when males grasp females,

211 they serve as courtship displays. Courtship lasted a maximum of $23 \mathrm{~min}$, which is a substantial

212 amount of time, and is likely to be energetically expensive. This was an unexpected result,

213 because other small non-territorial damselflies do not have elaborate courtships, and suggests

214 that precopulatory sexual selection might be intense in this species. The complexity of this 
215 precopulatory courtship makes this species not only unique from its morphology and taxonomic

216 position but also ethologically. The specialized use of the legs to immobilise the female for long

217 periods is not found, to my knowledge, in other damselflies. The complete sequence of

218 precopulatory tandem and courtship might be primitive in comparison with other damselflies.

219 When small zygopterans are handled for marking, it is not rare that some loose one or more legs, 220 a fact that might reduce their survivorship (Cordero-Rivera, Egido Pérez \& Andrés, 2002). In the 221 case of $H$. mirabilis this never happened, and all individuals had six legs when first captured.

222 Furthermore, I found that pulling off legs out from adult $H$. mirabilis to sample tissues for DNA, 223 required the use of scissors instead of forceps, because forcibly removing one leg could damage

224 the animal due to muscular tissues remaining attached to the leg. Given that legs are used to 225 immobilise females during courtship (Figures 1 and 2), perhaps this explains why H. mirabilis 226 males do not autotomise their legs. Legs are crucial for male courtship in H. mirabilis, another 227 unusual characteristic.

228 A third peculiarity of $H$. mirabilis is that mating frequency is surprisingly low. Even if males and 229 females were observed in large numbers, they seldom interacted. The rarity of mating 230 interactions seems the norm among Amazonian rainforest odonates (Rhainer Guillermo, pers. 231 comm. 2016 and also pers. obs.), which have low densities and live for weeks or months, but it is 232 certainly surprising for an animal with a high density and low daily survivorship like $H$. mirabilis 233 (Cordero-Rivera, 2016). This low mating frequency, combined with the intense precopulatory 234 sexual selection during courtship and lack of postcopulatory association between males and 235 females, which is typical when polyandry is common (Alcock, 1994), suggest that females mate 236 very few times during their lifetime. This is further indicated by the finding that two out of seven 237 pre-copula females and two out of eight females interrupted at the end of stage I of copulation 
238 had no sperm from previous matings, which suggests that they were unmated or might be mating

239 for the first time.

240 Even if mating frequency is low, it is unlikely that female $H$. mirabilis is monogamous. The

241 anatomy of genitalia is typical of sperm removers, and the measurement of sperm volumes

242 confirmed this possibility. Comparison of Figures 7A and 7B show that the size and morphology

243 of genital ligula match the size and morphology of female genitalia. The images in Figure 7 are

244 oriented with the dorsal part above, but during copulation, the abdomen of the female contacts

245 with the male upside-down as in Figure 4. During copulation, the foldable tip of the genital ligula

246 is oriented in a way that favours the introduction of its horns into the bursa, facilitating sperm

247 capture and removal. This positioning was confirmed in one pair preserved in copula. In all

248 Zygopteran species so far studied, stage I is used to remove sperm from previous matings and

249 stage II to inseminate (Córdoba-Aguilar, Uhía \& Cordero-Rivera, 2003). My results are

250 compatible with this scenario also for $H$. mirabilis. Therefore, sperm competition has been a

251 relevant force in the evolution of reproductive behaviour in this species, and given its

252 phylogenetic position in the order Odonata, it may date back to the Permian. A study of the

253 evolution of genitalia in a phylogenetic context is certainly a priority (e.g. Rudoy \& Ribera,

254 2016). Two (out of nine) females dissected after a complete copulation did not have sperm in

255 their bursa. This suggests that some matings might be unsuccessful at insemination, and

256 therefore females may need to mate more than once to be able to reproduce. This possibility

257 needs further study.

258 I did not observe oviposition, including trying to elicit egg-laying on humid filter paper and plant

259 tissue. Oviposition has apparently never been observed in this species (Sant \& New, 1988). The

260 dense vegetation of Long Swamp was too complex to allow detailed behavioural observations of 
261 these small damselflies. If females lay eggs at the base of the reeds, this is unlikely to be

262 detected. Even mating pairs were very difficult to observe among the vegetation. Furthermore,

263 individuals in copula were never seen flying (a further peculiarity of this species), which also

264 makes detection difficult. Focal observation of 79 females in this population (each with a

265 duration of $10 \mathrm{~min}$ ) allowed witnessing three of them mating, but none laying eggs (Cordero-

266 Rivera, 2016). One possibility is that oviposition takes place at night. Nevertheless, this seems

267 unlikely because Hemiphlebia showed no activity at low temperatures, and five females were

268 confined overnight with humid filter paper, and did not lay eggs. Further detailed observations at

269 localities where the vegetation is less dense (e.g. Ming Ming swamp) might allow one to detect

270 oviposition, which surely is endophytic given the structure of the ovipositor (Sant \& New, 1988).

271 To conclude, this study offers the first description of reproductive behaviour of a key taxon in

272 the evolution of the Odonata, considered the sister group to all Lestoidea (Dumont, Vierstraete \&

273 Vanfleteren, 2010), and suggests that sperm removal is an old adaptive trait within male

274 odonates in the arena of sexual selection. Some mysteries remain: "Hemiphlebia mirabilis will

275 always be an enigma" (Fraser, 1955).

\section{Acknowledgements}

277 I acknowledge the help of many colleagues, which shared with me their experiences and

278 information about the fascinating H. mirabilis during my sabbatical leave in Nov-Dec 2013, with

279 a license from the University of Vigo. Many thanks to Di Crowther, Ian Endersby, Gerry Quinn,

280 John Hawking, Reiner Ritchter, and Richard Rowe. I am grateful to Natalia von Ellenrieder and

281 Rosser W. Garrison for their useful comments. 


\section{References}

283 Alcock J. 1994. Postinsemination associations between males and females in insects: The mate 284 guarding hypothesis. Annual Review of Entomology 39:1-21.

285 Andersson M. 1994. Sexual selection. Princeton: Princeton University Press.

286 Arnqvist G. 2004. Sexual conflict and sexual selection: lost in the chase. Evolution 58:1383$287 \quad 1388$.

288 Clutton-Brock T. 2007. Sexual selection in males and females. Science 318:1882-1885.

289 Cordero A., Miller PL. 1992. Sperm transfer, displacement and precedence in Ischnura graellsii 290 (Odonata: Coenagrionidae). Behavioral Ecology and Sociobiology 30:261-267.

291 Cordero Rivera A., Córdoba-Aguilar A. 2016. Selección postcópula: competencia espermática y 292 elección femenina críptica. In: Carranza J ed. Etología adaptativa: el comportamiento como 293 producto de la selección natural. UCOpress y Publicaciones de la Universidad de $294 \quad$ Extremadura, 471-497.

295 Cordero-Rivera A. 2016. Demographics and adult activity of Hemiphlebia mirabilis: a short296 lived species with a huge population size (Odonata: Hemiphlebiidae). Insect Conservation 297 and Diversity 9:108-117. DOI: 10.1111/icad.12147.

298 Cordero-Rivera A., Córdoba-Aguilar A. 2010. Selective forces propelling genitalic evolution in 299 Odonata. In: Leonard J, Córdoba-Aguilar A eds. The evolution of primary sexual characters 300 in animals. Oxford: Oxford University Press, 332-352.

301 Cordero-Rivera A., Egido Pérez FJ., Andrés JA. 2002. The effect of handling damage, mobility, 302 body size, and fluctuating asymmetry on lifetime mating success of Ischnura graellsii 303 (Rambur) (Zygoptera: Coenagrionidae). Odonatologica 31:117-128. 
304 Cordero-Rivera A., Stoks R. 2008. Mark-recapture studies and demography. In: Córdoba305 Aguilar A ed. Dragonflies: model organisms for ecological and evolutionary studies. 306 Oxford: Oxford University Press, 7-20. DOI:

307 10.1093/acprof:oso/9780199230693.003.0002.

308 Córdoba-Aguilar A. 2006. Sperm ejection as a possible cryptic female choice mechanism in 309 Odonata (Insecta). Physiological Entomology 31:146-153.

310 Córdoba-Aguilar A. 2008. Dragonflies and damselflies. Model organisms for ecological and 311 evolutionary research. Oxford: Oxford University Press.

312 Córdoba-Aguilar A., Cordero-Rivera A. 2008. Cryptic female choice and sexual conflict. In: 313 Córdoba-Aguilar A ed. Dragonflies: model organisms for ecological and evolutionary 314 studies. Oxford: Oxford University Press, 189-202.

315 Córdoba-Aguilar A., Uhía E., Cordero-Rivera A. 2003. Sperm competition in Odonata (Insecta): 316 the evolution of female sperm storage and rivals' sperm displacement. Journal of Zoology $317 \quad 261: 381-398$.

318 Darwin C. 1871. The descent of man and selection in relation to sex. London: John Murray.

319 Davies DAL. 1985. Hemiphlebia mirabilis Selys: some notes on distribution and conservation 320 status (Zygoptera: Hemiphlebiidae). Odonatologica 14:331-339.

321 Dumont HJ., Vierstraete A., Vanfleteren JR. 2010. A molecular phylogeny of the Odonata 322 (Insecta). Systematic Entomology 35:6-18.

323 Eberhard WG. 1985. Sexual selection and animal genitalia. Cambridge, Massachusetts: Harvard $324 \quad$ University Press.

325 Eberhard WG. 1996. Female control: sexual selection by cryptic female choice. Princeton: 
327 Fraser FC. 1955. A study of Hemiphlebia mirabilis Selys (Odonata), a survival from the 328 Permian. Entomologists Monthly Magazine 91:110-113.

329 Galeotti P., Rubolini D., Pupin F., Sacchi R., Fasola M. 2008. Sperm removal and ejaculate size 330 correlate with chelae asymmetry in a freshwater crayfish species. Behavioral Ecology and 331 Sociobiology 62:1739-1745. DOI: 10.1007/s00265-008-0602-8.

332 Van Gossum H., Sánchez-Guillén RA., Cordero-Rivera A. 2003. Observations on rearing 333 damselflies under laboratory conditions. Animal Biology 53:37-45.

334 von Helversen D., von Helversen O. 1991. Pre-mating sperm removal in the bushcricket 335 Metaplastes ornatus Ramme 1931 (Othoptera, Tettigonoidea, Phaneropteridae). Behavioral 336 Ecology and Sociobiology 28:391-396.

337 Kamimura Y. 2005. Last-male paternity of Euborellia plebeja, an earwig with elongated genitalia and sperm-removal behavior. Journal of Ethology 23:35-41. DOI: 10.1007/s10164-0040125-3.

Lak M., Fleck G., Azar D., Engel Fls MS., Kaddumi HF., Neraudeau D., Tafforeau P., Nel A., Engel MS., Kaddumi HF., Neraudeau D., Tafforeau P., Nel A. 2009. Phase contrast X-ray synchrotron microtomography and the oldest damselflies in amber (Odonata: Zygoptera: Hemiphlebiidae). Zoological Journal of the Linnean Society 156:913-923. DOI:

345 Leonard J., Córdoba-Aguilar A. 2010. The evolution of primary sexual characters in animals. 346 Oxford: Oxford University Press.

347 Miller PL., Miller CA. 1981. Field observations on copulatory behaviour in Zygoptera, with an 

examination of the structure and activity of male genitalia. Odonatologica 10:201-218.

349 Ono T., Siva-Jothy MT., Kato A. 1989. Removal and subsequent ingestion of rivals' semen 350 during copulation in a tree cricket. Physiological Entomology 14:195-202.

351 Parker GA. 1979. Sexual selection and sexual conflict. In: Blum MS, Blum NA eds. Sexual 352 selection and reproductive competition in insects. New York: Academic Press, 123-166.

Rudoy A., Ribera I. 2016. The macroevolution of size and complexity in insect male genitalia. PeerJ In press.

Sánchez V., Cordero C. 2014. Sexual coevolution of spermatophore envelopes and female genital traits in butterflies: Evidence of male coercion? PeerJ 2:e247. DOI: $10.7717 /$ peerj. 247 .

Sánchez-Guillén RA., Wellenreuther M., Cordero-Rivera A. 2011. Strong asymmetry in the relative strengths of prezygotic and postzygotic barriers between two damselfly sister

Sant GJ., New TR. 1988. The biology and conservation of Hemiphlebia mirabilis Selys (Odonata, Hemiphlebiidae) in southern Victoria. Melbourne: Department of Conservation Forests and Lands.

Tillyard RJ. 1913. On some new and rare Australian Agrionidae (Odonata). Proceedings of the 365 Linnean Society of New South Wales 37:404-479.

Waage JK. 1979. Dual function of the damselfly penis: sperm removal and transfer. Science 203:916-918.

368 Wada T., Takegaki T., Mori T., Natsukari Y. 2010. Sperm removal, ejaculation and their 369 behavioural interaction in male cuttlefish in response to female mating history. Animal 
370 Behaviour 79:613-619. DOI: 10.1016/j.anbehav.2009.12.004.

371 Yokoi N. 1990. The sperm removal behavior of the Yellow Spotted Longicorn Beetle Psacothea 372 hilaris (Coleoptera: Cerambycidae). Applied Entomology and Zoology 25:383-388.

373

374

375

376 Supplementary material

377 Video 1. A summary of reproductive behaviour of $H$. mirabilis.

378 Available at: https://youtu.be/YpYHwe8JD10 


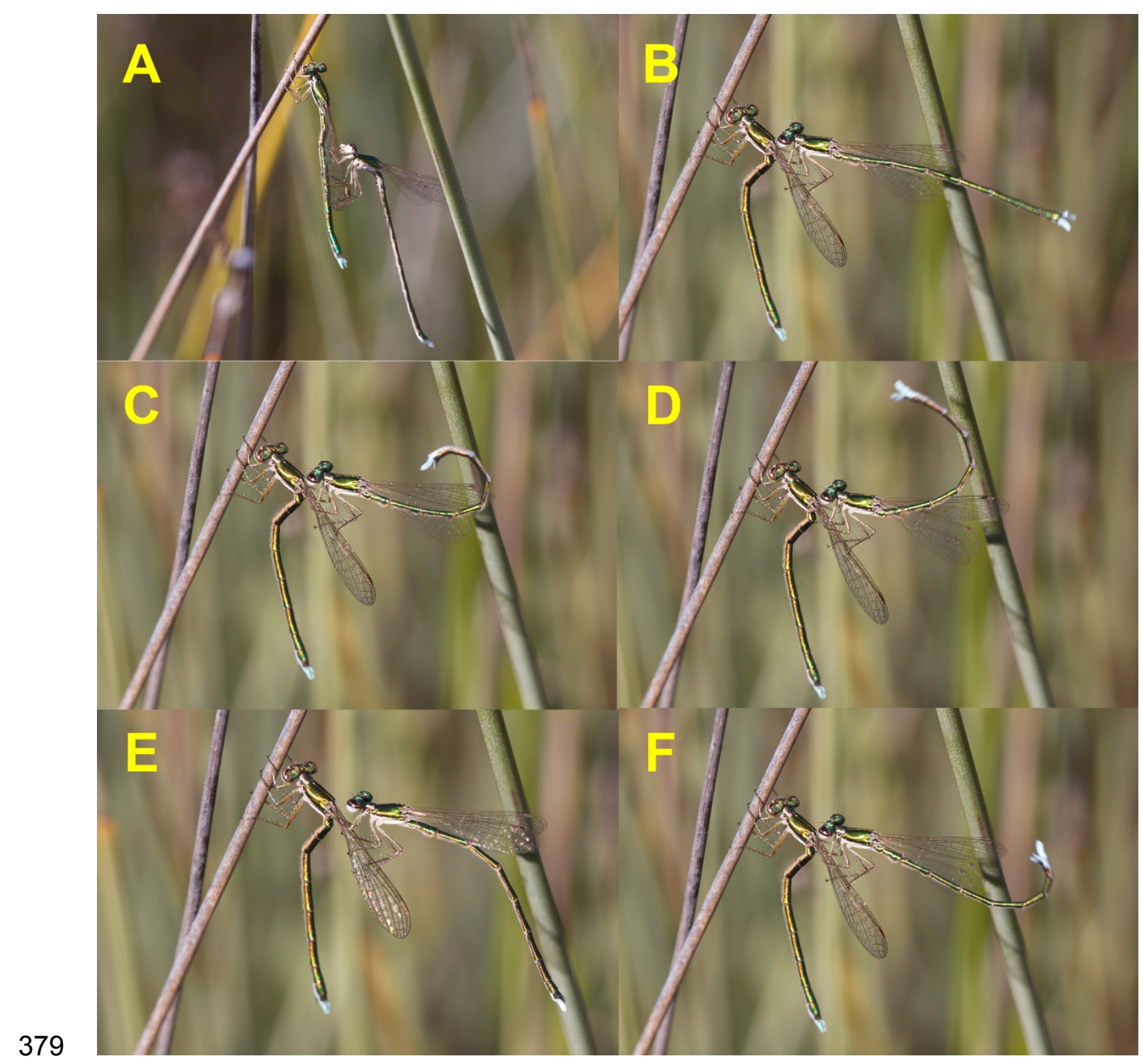

380 Figure 1. Courtship behaviour of male H. mirabilis. Males use the "flicking" display

381 characteristic of this species. Note the "Z" position of female abdomen, which signals

382 receptivity. Males repeatedly curl their abdomen up and downwards during this display. See also

383 Video 1. 


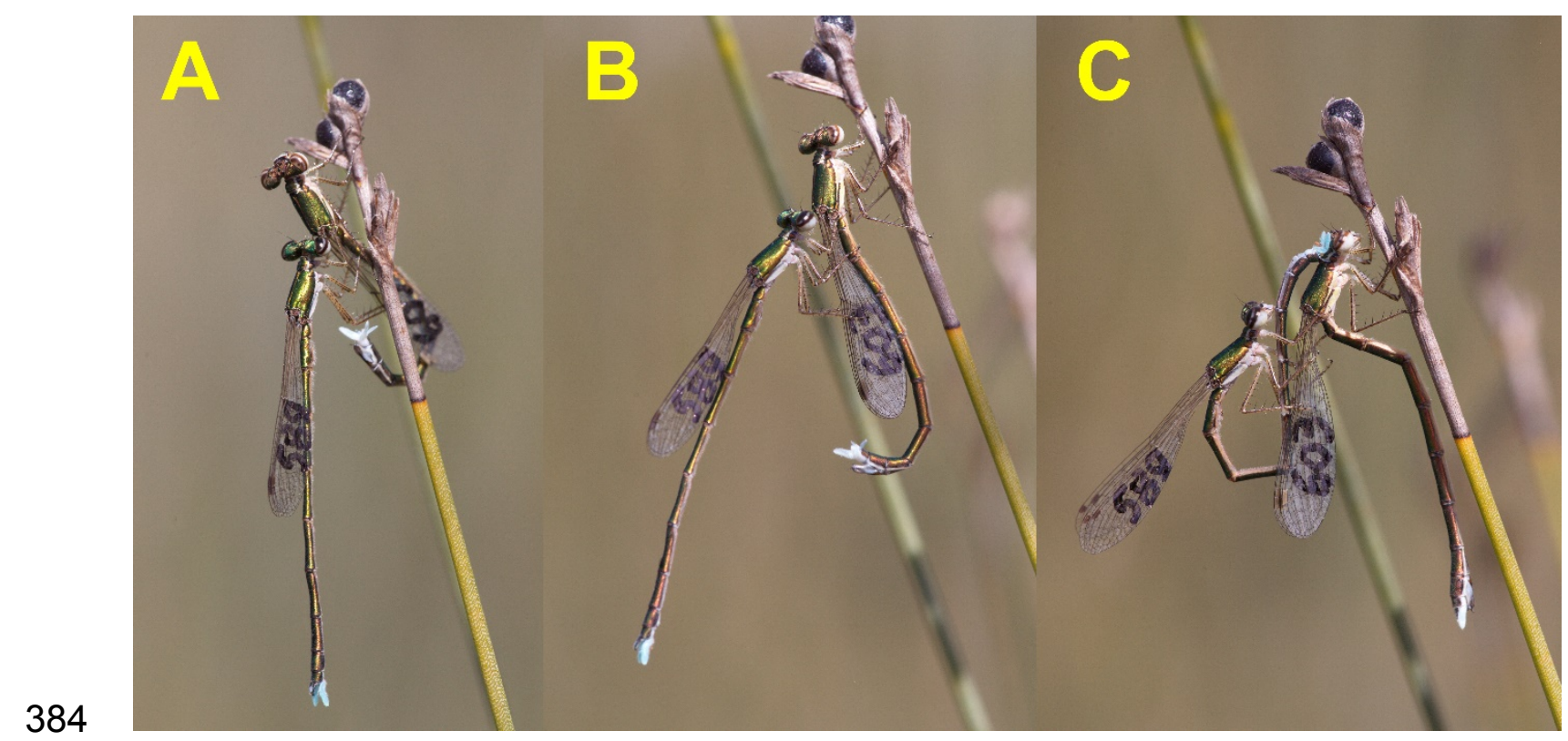

385 Figure 2. Female refusal behaviour, using the abdomen to try to dislodge the male (A and B), and

386 the start of precopulatory tandem (C), once female shows signs of receptivity. Female acceptance 387 of copulation is indicated by the " $Z$ " position of her abdomen. 
390 Figure 3. Intra-male sperm translocation behaviour. All matings observed $(\mathrm{N}=28)$ were preceded 391 by this behaviour. 


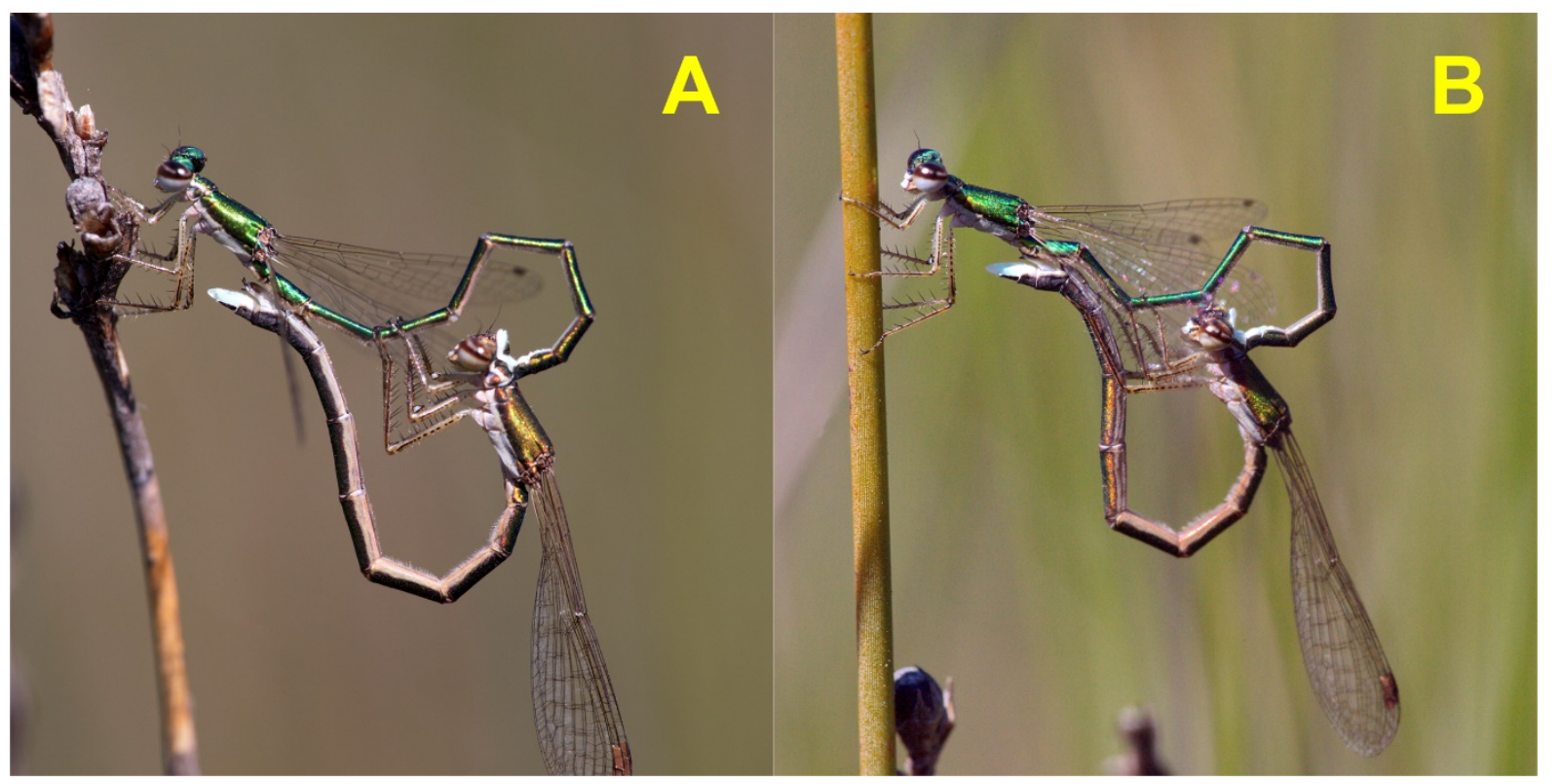

395 of Miller and Miller (1981). Stage I is involved in rivals' sperm removal and insemination takes 396 place during stage II. 


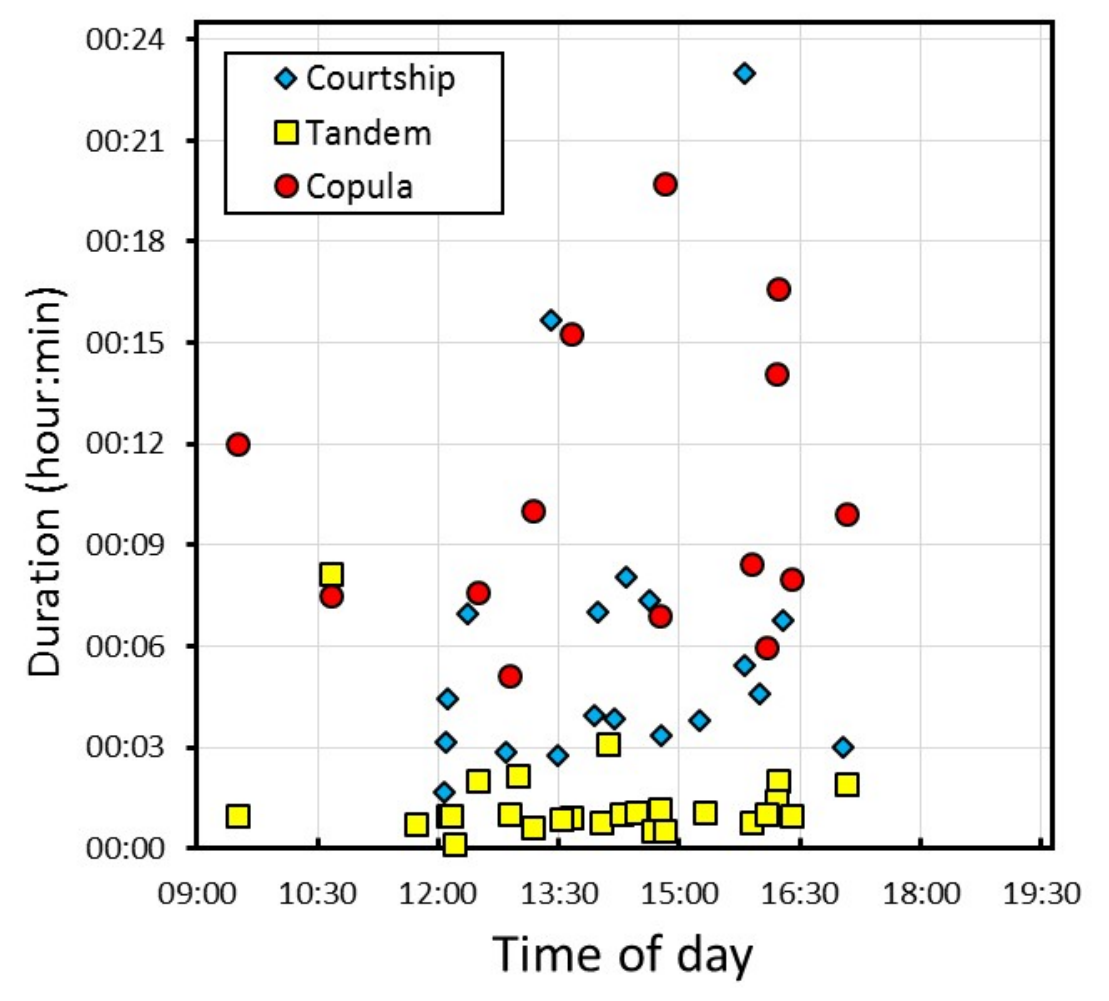

399 Figure 5. Relationship between time of day and duration of reproductive behaviours of $H$.

400 mirabilis. Courtship refers to the time between female capture and tandem formation. Tandem

401 indicates the time the pair remained in tandem before copulation. Finally, copulation refers to the 402 time between the start and the end of the copulatory wheel.

403 


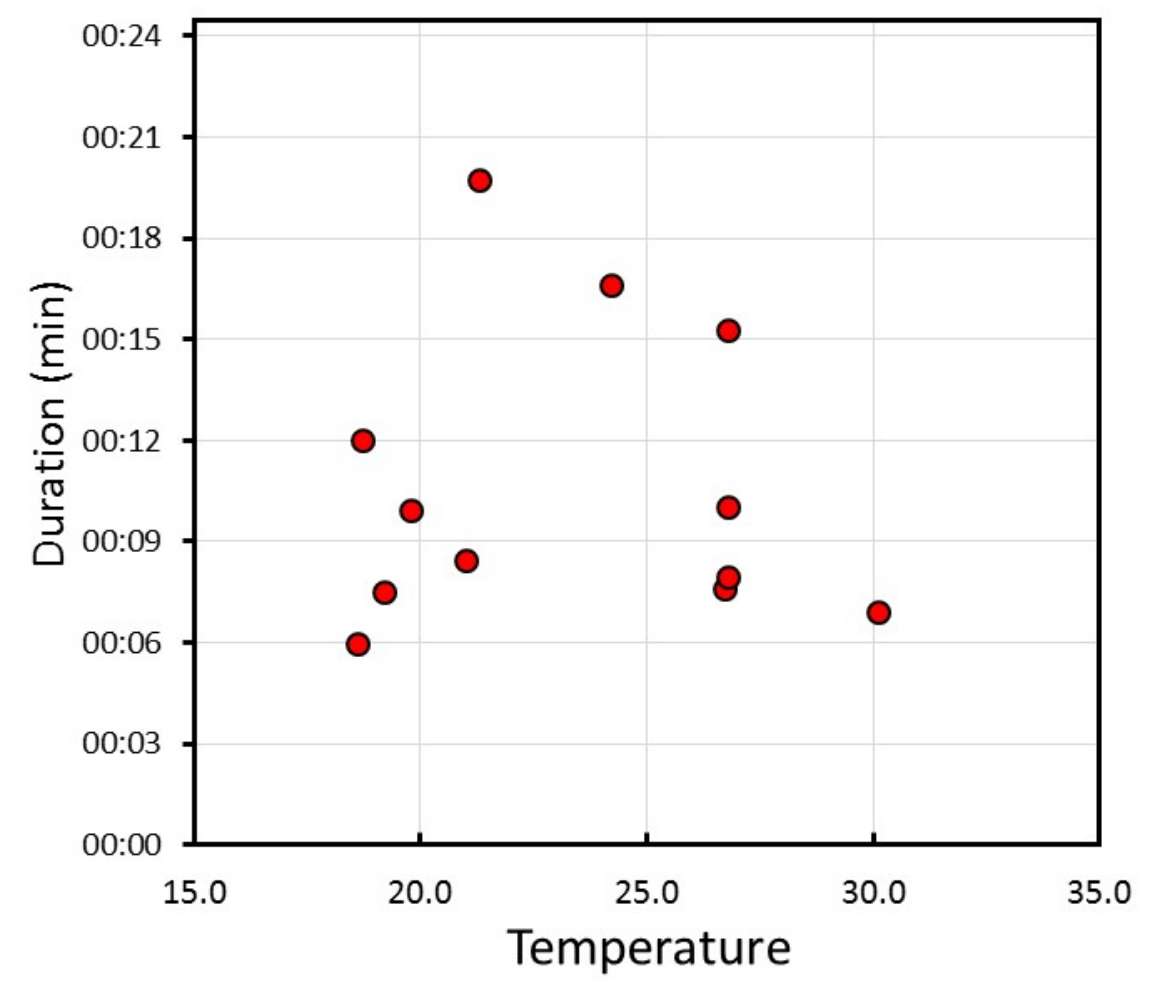

404

405 Figure 6. Relationship between air temperature and copulation duration in H. mirabilis. 

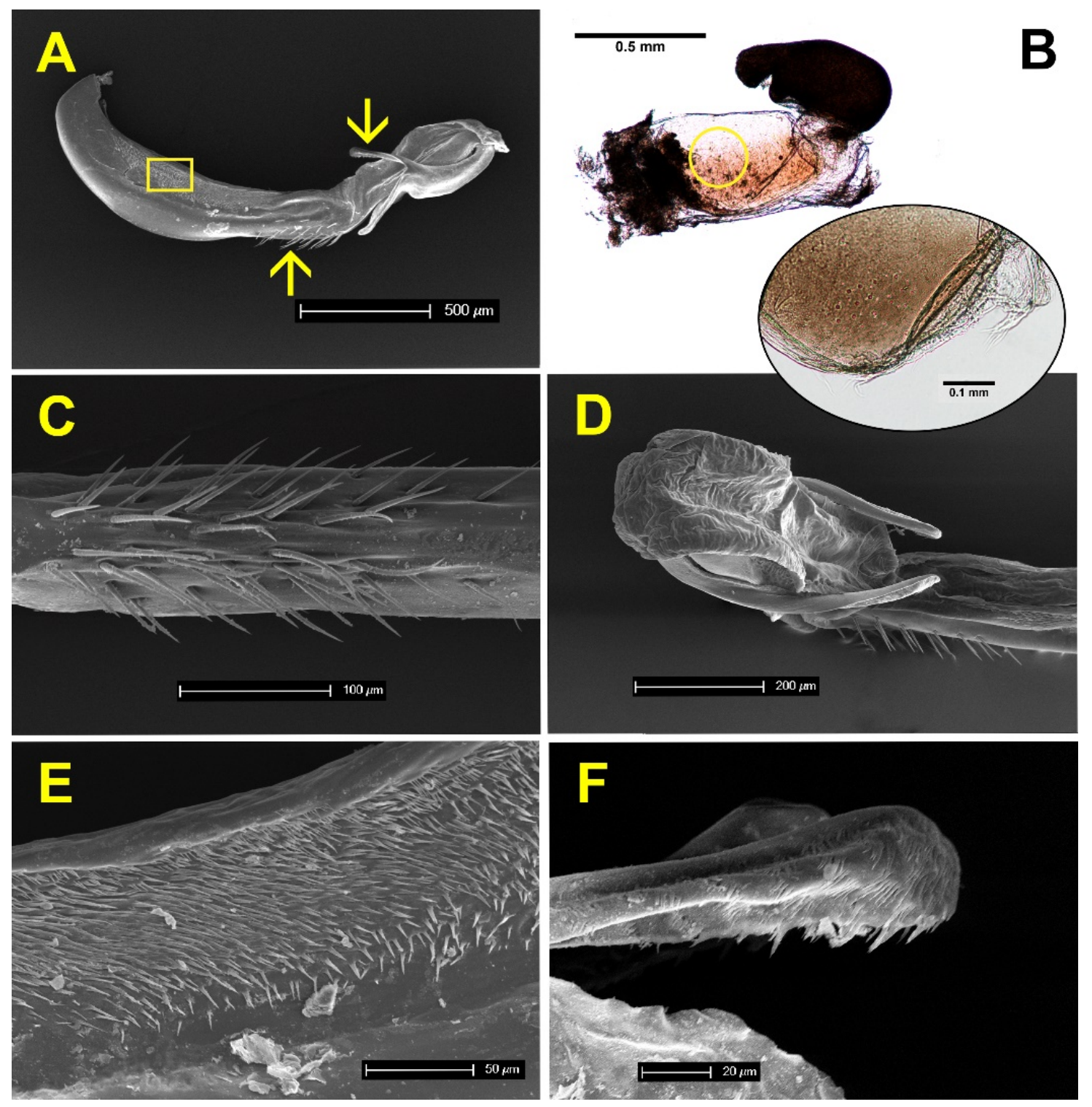

408 Figure 7. Male and female genitalia of $H$. mirabilis. (A) Lateral view of genital ligula and (B)

409 female vagina and bursa copulatrix, both at the same scale, and oriented with the dorsal part

410 above. The insert in (B) shows a detail of the genital valves of the female, which are provided

411 with mechanical sensilla, situated in the area indicated by the circle. Further details of male

412 genital ligula are shown. (C) Ventral view of the spines, in the region indicated by the upwards

413 arrow in (A). (D) Dorso-lateral view of the tip of the genital ligula. (E) Detail of the spines of the

414 genital ligula in the region indicated by the rectangle in (A). (F) Lateral view of the genital ligula 
415 distal horns, with backward-directed spines, whose position is indicated by the downward arrow

416 in (A). The image in (B) has been edited to remove dust. 


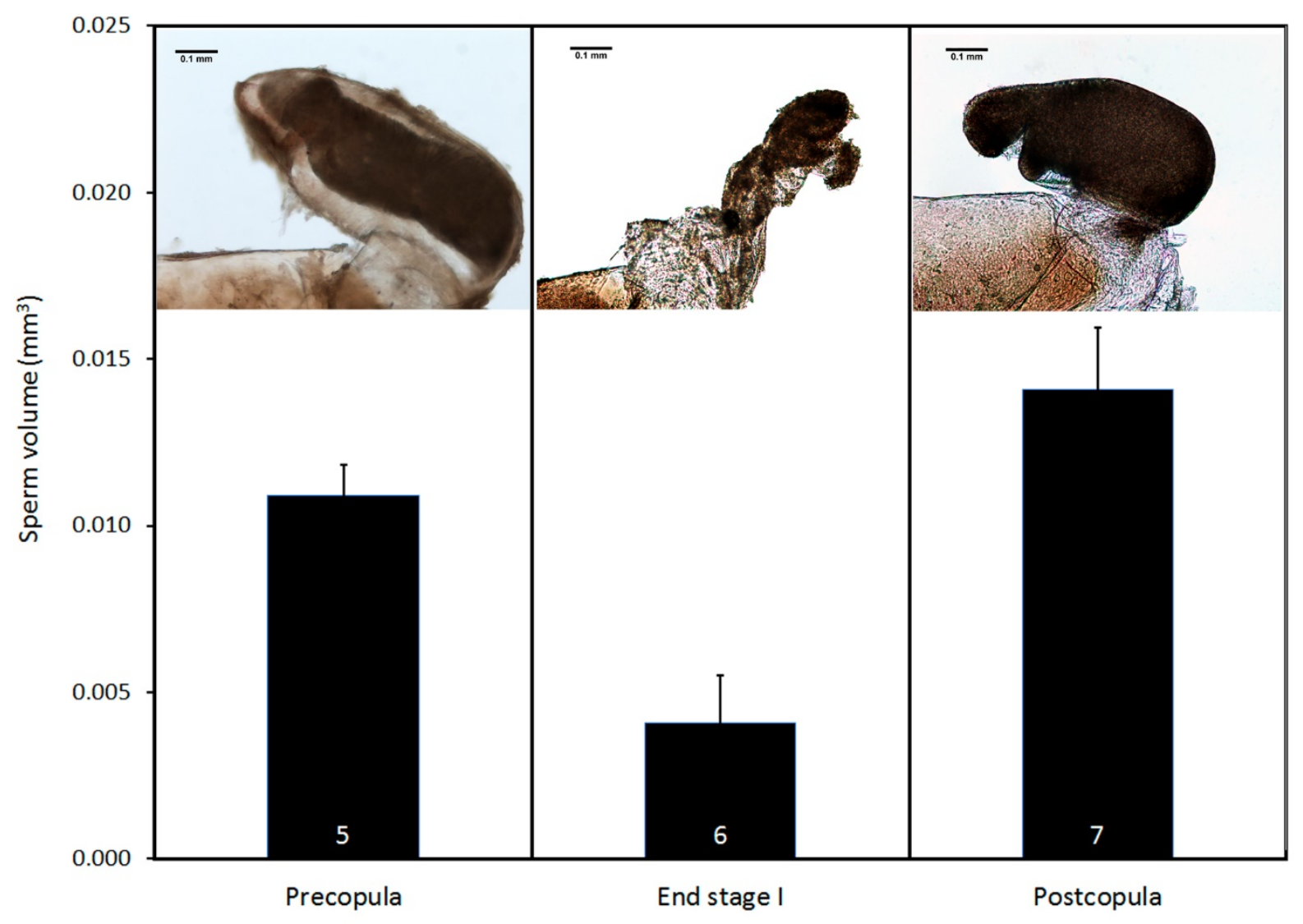

418 Figure 8. Volume of sperm (mean+SE) in females collected before mating, interrupted at the end

419 of stage I before insemination, and after one complete copulation. Numbers are sample size. The

420 pictures show examples of the bursa copulatrix full of sperm before and after copulation (left

421 and right) and partially emptied at the end of stage I (centre). Scale bar in the images $0.1 \mathrm{~mm}$.

422 Images edited to remove dust. 